\title{
Influence of $17 \beta$-Estradiol, Progesterone, and Dexamethasone on Diapedesis and Viability of Bovine Blood Polymorphonuclear Leukocytes
}

\author{
I. Lamote, E. Meyer, L. Duchateau, and C. Burvenich \\ Department of Physiology, Biochemistry and Biometrics, \\ Faculty of Veterinary Medicine, Ghent University, \\ B-9820 Merelbeke, Belgium
}

\begin{abstract}
The aim of the current study was to investigate whether polymorphonuclear leukocyte (PMN) diapedesis and viability are influenced by steroid hormones. Using an in vitro model with different types of cell layers (bovine mammary epithelial cells and fibroblasts), we investigate whether steroid hormone treatments (17 $\beta$-estradiol, progesterone, and dexamethasone) have an influence on the diapedesis capacity and viability of PMN. In addition, we studied apoptosis of $\mathrm{PMN}$ in the in vitro model and evaluated the influence of different types of cell layers and steroid hormone treatments on this process. A significant decrease in the number of viable PMN in the lower compartment of the in vitro model (i.e., number of migrated PMN $\times$ viability after migration) was found after $17 \beta$-estradiol treatment, whereas no influence was detected after progesterone or dexamethasone treatment. The effect of $17 \beta$-estradiol was not due to a lower viability before migration as none of the treatments caused a significant effect on the viability before diapedesis. This treatment effect was not influenced by endogenous $17 \beta$-estradiol or progesterone levels before isolation because there was no correlation between these plasma levels and PMN diapedesis capacity or viability. Furthermore, migration through epithelial cells caused a significant decrease in viability of PMN due to increased apoptosis but not necrosis.
\end{abstract}

(Key words: steroid, diapedesis, viability, polymorphonuclear leukocyte)

Abbreviation key: BME = bovine mammary epithelial, HBSS = Hank's balanced salt solution, PI = propidium iodide, PMN = polymorphonuclear leukocytes, ZAS = zymosan-activated serum.

Received February 13, 2004.

Accepted May 21, 2004.

Corresponding author: C. Burvenich; e-mail: christian.burvenich @ugent.be.

\section{INTRODUCTION}

The bovine mammary gland is constantly challenged by a variety of contagious and environmental pathogens (Burton and Erskine, 2003; Burvenich et al., 2003). Polymorphonuclear leukocytes (PMN), the major constituent of the granulocyte cell population, play a central role in early defense against most bacterial infections (Burvenich et al., 2003). To combat an infection, circulating PMN have to attach to the endothelium and migrate (diapedesis) from blood through the endothelium, subepithelial matrix, basement membrane, and mammary epithelium following a chemoattractant gradient to the site of infection (Smits et al., 1996). As inflammation proceeds or infection subsides, PMN are removed from the site of infection, mainly by apoptosis, to prevent tissue necrosis (Sladek and Rysanek, 2000). Deficiencies in any of these steps could lead to recurrent and life-threatening infections (Osterlundh et al., 2002).

The incidence of infection depends on the stage of lactation and is usually highest after calving and at drying off (Burvenich et al., 1999). In addition, PMN function varies with stage of lactation, concomitant with variations in steroid hormone concentrations (Osterlundh et al., 2002). During the periparturient period, cows are subjected to major changes in sex steroid hormone levels that may induce suppression of immune function. In the last week before parturition, plasma concentrations of $17 \beta$-estradiol may rise steeply, peaking in the last $3 \mathrm{~d}$ before delivery but then falling rapidly to regain basal values directly after calving. During the last month of gestation, the high plasma concentration of progesterone declines, but a dramatic fall usually occurs only in the last $2 \mathrm{~d}$ before delivery. It is not yet fully understood how these changes in sex steroid concentrations relate to changes in immune response.

Once their function in the inflammatory foci is performed, PMN need to die by apoptosis. The local regulation of PMN apoptosis within the mammary gland is not yet fully understood, although it may contribute to the reported decreased viability of milk PMN compared 
with blood PMN (Mehrzad et al., 2001). Moreover, low viability of resident milk PMN is observed during early lactation (Burvenich et al., 2003), suggesting a potential influence of changed physiological factors such as $17 \beta$-estradiol and progesterone on the viability of migrated PMN.

It is also evident that many of the PMN functions likely to be induced during inflammation, are affected by glucocorticosteroids (Cox, 1995). Dexamethasone causes inhibition of apoptosis in human PMN (Cox, 1995; Kato et al., 1995; Liles et al., 1995; Meagher et al., 1996; Cox and Austin, 1997; Nittoh et al., 1998) as well as an increased chemotactic ability of bovine PMN (Anderson et al., 1999). Both effects may stimulate resolution of inflammation, if the delay in PMN apoptosis is not followed by PMN necrosis. It should also be noted that contradictory results on the effect of dexamethasone have been reported.

The aim of the current study was to investigate, using an in vitro model with different types of cell layers (bovine mammary epithelial cells and fibroblasts), whether different steroid hormone treatments (17 $\beta$-estradiol, progesterone, and dexamethasone) have an influence on the PMN diapedesis capacity and viability. In addition, PMN viability was further differentiated into apoptosis vs. necrosis.

\section{MATERIALS AND METHODS}

\section{Culture of Bovine Mammary Epithelial Cells}

Bovine mammary epithelial cells (BME-UV1) were purchased from Istituto Zooprofilattico Sperimentale Della Lombardia e Dell' Emilia-Romagna, Brescia, Italy, and have previously been described by Zavizion et al. (1996). Briefly, the BME-UV1 cell line is a clonal cell line established from primary BME by stable transfection with a plasmid, which carries the sequence of the simian virus SV40 early region mutant tsA58, encoding the thermolabile large $\mathrm{T}$ antigen. The cells express functional markers such as microvilli and desmosomes and biochemical markers of mammary epithelial cells such as cytokeratins. The BME-UV1 cell line is capable of synthesizing low levels of $\alpha$-lactalbumin and $\alpha$ s1-casein. Culture medium contained 40\% Ham's F12, 30\% RPMI 1640, 20\% NCTC 135, $10 \%$ fetal calf serum (all from Gibco BRL, Life Technologies Inc., Gaithersburg, $\mathrm{MD}), 2 \%$ antibiotic-antimycotic solution, $0.1 \%$ lactose, $0.1 \%$ lactalbumin hydrolysate, $1.2 \mathrm{~m} M$ glutathione, 10 $\mu \mathrm{g} / \mathrm{mL}$ L-ascorbic acid, $1 \mu \mathrm{g} / \mathrm{mL}$ hydrocortisone, and 1 $\mu \mathrm{g} / \mathrm{mL}$ insulin (all from Sigma Chemical Co., St. Louis, MO). Stock cell cultures $\left(3 \times 10^{6}\right.$ cells $)$ were grown in $75-\mathrm{cm}^{2}$ tissue culture treated, vented flasks containing $20 \mathrm{~mL}$ of the culture medium. Half of the medium was refreshed every $2 \mathrm{~d}$. Cells were subcultured once every
3 to $5 \mathrm{~d}$ when flasks were 70 to $80 \%$ confluent. Passage of cells in the flasks was performed by aspirating the medium, rinsing with $10 \mathrm{~mL}$ of PBS (Sigma Chemical Co.), and then incubating the cells with $10 \mathrm{~mL}$ of a $0.05 \%$ trypsin-EDTA solution for $5 \mathrm{~min}$ at $37^{\circ} \mathrm{C}$ in $5 \%$ $\mathrm{CO}_{2}$. Once the cells detached, they were suspended in $15 \mathrm{~mL}$ of fetal calf serum, and centrifuged $(221 \times \mathrm{g}$ for $5 \mathrm{~min})$. The supernatant was removed and the cells were counted with a Coulter counter (Coulter counter ZF, Coulter Electronics Ltd., Luton, UK).

\section{Culture of Fibroblasts}

Fibroblasts (bovine dermal fibroblasts) were purchased from Istituto Zooprofilattico Sperimentale Della Lombardia e Dell' Emilia-Romagna. Stock cell cultures (3 to $4 \times 10^{6}$ cells) were grown and trypsinized as described for BME-UV1.

\section{Coating of Synthetic Membrane Inserts with Collagen}

Membrane inserts (12 mm diameter, $3 \mu \mathrm{m}$ pore size, Millicell-PCF, Millipore Corp., Bedford, MA) were coated with a commercial $0.1 \%$ calfskin collagen (type I) solution (Sigma Chemical Co.) by adding $100 \mu \mathrm{L}$ of this solution to both sides of the inserts. The inserts were dried overnight at room temperature under a laminar airflow hood.

\section{In Vitro Model with Bovine Mammary Epithelial Cells}

Inverted collagen-coated inserts were placed in 6-well tissue culture plates with both surfaces bathed in 8 $\mathrm{mL}$ of culture medium and seeded with $75 \mu \mathrm{L}$ of an epithelial cell suspension containing $3 \times 10^{5}$ cells $/ \mathrm{mL}$. Inserts were kept in a $5 \% \mathrm{CO}_{2}$ incubator at $37^{\circ} \mathrm{C}$; half of the medium was changed every $2 \mathrm{~d}$. On $\mathrm{d} 15$, inserts were used for the experiment. In parallel, some inserts were used for scanning electron microscopy and microtomy as an extra morphological control of the confluence of the BME-UV1 layers.

\section{In Vitro Model with Bovine Mammary Epithelial Cells and Fibroblasts}

Fibroblasts $\left(1.5 \times 10^{5}\right.$ cells $\left./ \mathrm{mL}\right)$ were plated on the inverted collagen-coated inserts and incubated at $37^{\circ} \mathrm{C}$ in $5 \% \mathrm{CO}_{2}$ for $12 \mathrm{~h}$. After $12 \mathrm{~h}$, inserts were irradiated with UV light for $5 \mathrm{~min}$ to inhibit fibroblast overgrowth in the model. One hundred microliters of $0.1 \%$ calfskin collagen solution was layered onto the irradiated fibroblasts and the model was incubated at $37^{\circ} \mathrm{C}$ in $5 \% \mathrm{CO}_{2}$. 
After $3 \mathrm{~h}, \mathrm{BME}-\mathrm{UV} 1$ cells were added and incubated at $37^{\circ} \mathrm{C}$ in $5 \% \mathrm{CO}_{2}$ for $15 \mathrm{~d}$. Half of the culture medium was changed every $2 \mathrm{~d}$. In parallel, some inserts were used for scanning electron microscopy and microtomy as an extra control of the confluence of the BME-UV1 layers.

\section{Determination of Transepithelial Resistance}

Confluence of the monolayers was determined by transepithelial electrical resistance. Transepithelial electrical resistance was measured using an Ohmmeter (World Precision Instruments, New Haven, CT). Collagen-coated inserts with fibroblasts served as a control. Inserts with a transepithelial electrical resistance higher than $800 \Omega \times \mathrm{cm}^{2}$ were used in the experiment, because a resistance of $800 \Omega \times \mathrm{cm}^{2}$ and higher has been shown to give good resistance against trypan blue diffusion during more than 120 min (data not shown).

\section{Isolation of PMN}

Fifteen clinically healthy Holstein cows in their last $4 \mathrm{wk}$ of gestation were selected. Seven cows were used for the study of the influence of $17 \beta$-estradiol, progesterone, and dexamethasone on the diapedesis of PMN through different cell layers. To study the influence of $17 \beta$-estradiol and progesterone on the migration through collagen-coated inserts, 8 extra cows were used. The cows were used after approval by the Ethical Committee of the Faculty of Veterinary Medicine, University Ghent, Belgium. Blood for PMN isolation was collected via venipuncture of the jugular vein using 60 $\mathrm{mL}$ sterile tubes containing $30 \mathrm{~mL}$ of Alsever solution as anticoagulant $(0.42 \% \mathrm{NaCl}, 0.8 \%$ trisodium citrate, $2.05 \%$ glucose in PBS adjusted to $\mathrm{pH} 6.1$ by addition of a $10 \%$ solution of citric acid). Polymorphonuclear leukocytes were isolated using the method described by Roets et al. (1999) using $\mathrm{NH}_{4} \mathrm{Cl}$ for lysis of erythrocytes after removal of the buffy coat. The cell pellets comprising isolated PMN were then resuspended and the cell concentration of the suspension was determined using a Coulter counter. The concentration of cells was then adjusted to $8.3 \times 10^{6}$ cells $/ \mathrm{mL}$ with Hank's balanced salt solution (HBSS) containing $0.1 \%$ BSA.

\section{Analysis of $17 \beta$-Estradiol and Progesterone Plasma Levels}

Plasma was removed after the first centrifugation step of the PMN isolation procedure and was stored at $-20^{\circ} \mathrm{C}$. Plasma levels of $17 \beta$-estradiol and progesterone were determined using a radioimmunoassay technique according to Henry et al. (1987). Briefly, the plasma concentration of $17 \beta$-estradiol was measured after extraction with diethylether without further purification, using an antiserum against estradiol-3-hemisuccinateBSA raised in sheep. The plasma concentration of progesterone was measured after extraction with petroleum ether without further purification, using an antiserum against progesterone-11-hemisuccinate-BSA raised in sheep. The detection limit in bovine plasma for $17 \beta$-estradiol and progesterone was $20 \mathrm{pg} / \mathrm{mL}$ and $0.5 \mathrm{ng} / \mathrm{mL}$, respectively. The intra- and interassay coefficients of variation were 5.75 and $8.30 \%$ for $17 \beta$-estradiol, and 7.05 and $8.75 \%$ for progesterone, respectively. Estrone was not determined in plasma.

\section{Incubation of PMN with $17 \beta$-Estradiol, Progesterone, and Dexamethasone}

Polymorphonuclear leukocytes were incubated with $1 \mathrm{ng} / \mathrm{mL}$ 17 $\beta$-estradiol (1,3,5(10)-Estratriene-3,17- $\beta$ diol), $50 \mathrm{ng} / \mathrm{mL}$ progesterone (4-Pregnene-3,20-dione), or $4 \mathrm{ng} / \mathrm{mL}$ dexamethasone (Sigma Chemical Co.) for $3 \mathrm{~h}$ at $37^{\circ} \mathrm{C}$. Stock solutions of $17 \beta$-estradiol, progesterone, and dexamethasone were prepared in $100 \%$ ethanol and diluted so that a final concentration of $0.1 \%$ ethanol was present in every steroid preparation, to obtain a constant solvent concentration. A control sample was run in parallel in which steroid hormones were replaced by medium (HBSS with $0.1 \%$ ethanol and $0.1 \%$ BSA).

\section{Preparation of Zymosan-Activated Serum}

A bovine serum pool was activated by incubating the serum with $15 \mathrm{mg} / \mathrm{mL}$ of zymosan (from Saccharomyces cerevisiae, Sigma Chemical Co.) at $37^{\circ} \mathrm{C}$ for $60 \mathrm{~min}$. After $1 \mathrm{~h}$ at $37^{\circ} \mathrm{C}$, the mixture was incubated at $56^{\circ} \mathrm{C}$ for 30 min to destroy complement components, with the exception of C5a. Component C5a is stable under these conditions (Rainard, 2003). Using heat inactivation, a stable C5a concentration is obtained in the serum, and formation of additional C5a during the diapedesis assay can be avoided. Zymosan particles were removed by centrifuging the mixture for $15 \mathrm{~min}$ at $2300 \mathrm{rpm}\left(4^{\circ} \mathrm{C}\right)$. The obtained supernatant was filtered through a 0.2$\mu \mathrm{m}$ filter (Millipore) and stored at $-80^{\circ} \mathrm{C}$ until use. For the PMN diapedesis assay, the zymosan-activated serum (ZAS) stock solution was diluted 1:5 with HBSS supplemented with $0.1 \%$ BSA. The concentration of C5a in the diluted ZAS solution was $456 \mathrm{ng} / \mathrm{mL}$. The concentration was determined using ELISA as described by Rainard et al. (1998).

\section{PMN Diapedesis Assay}

After $15 \mathrm{~d}$ of culture, inserts containing a confluent layer of epithelial cells were washed twice with HBSS 
containing $0.1 \%$ BSA. The inserts were placed upright in 24-well plates. Polymorphonuclear leukocytes $(2.5 \times$ $10^{6}, 300 \mu \mathrm{L}$ of an $8.3 \times 10^{6}$ cells $/ \mathrm{mL}$ suspension) were added on top of the inserts and stimulated to migrate across the membrane by the addition of $400 \mu \mathrm{L}$ of diluted ZAS to the lower well. The 24 -well plates were then placed into a $37^{\circ} \mathrm{C}$ incubator with $5 \% \mathrm{CO}_{2}$. After $2 \mathrm{~h}$, inserts were removed and the migrated PMN were counted in the lower well of the 24 -well plates.

\section{Flow Cytometric Analysis of PMN Viability Differentiated into Apoptosis and Necrosis}

Apoptosis and necrosis of bovine PMN was quantified using a dual-color flow cytometric procedure with staining of exposed phosphatidylserine with FITC-AnnexinV (Roche Diagnostics, Basel, Switzerland) and of cellular DNA with propidium iodide (PI) as described by Van Oostveldt et al. (1999). Briefly, labeling solution was prepared by adding $20 \mu \mathrm{L}$ of FITC-Annexin-V reagent and $10 \mu \mathrm{L}$ of PI solution $(50 \mu \mathrm{g} / \mathrm{mL})$ to $1000 \mu \mathrm{L}$ of incubation buffer (10 $\mathrm{m} M$ HEPES/NaOH, pH 7.4, $140 \mathrm{~m} M \mathrm{NaCl}, 5 \mathrm{mM} \mathrm{CaCl} \mathrm{Cl}_{2}$. Polymorphonuclear leukocytes $\left(1 \times 10^{5}\right)$ were centrifuged $(200 \times g, 10 \mathrm{~min})$ and resuspended in $100 \mu \mathrm{L}$ of labeling solution. The mixture was incubated for $10 \mathrm{~min}$ in the dark at room temperature and the cells were immediately analyzed by flow cytometry. Fluorescence was measured with a FACScan flow cytometer (Becton Dickinson Immunocytometry Systems, San Jose, CA). Dot plots were gated for PMN based on cell size by forward scattering and on granularity by side scattering. The gating of the PMN population was refined by defining the PMN population with the CH138 monoclonal antibody (VMRD Inc., Pullman, WA), an IgM isotype antibody that specifically recognizes bovine PMN. For this purpose, an extra aliquot of the isolated cell suspension of one cow $\left(1 \times 10^{6} /\right.$ $\mathrm{mL}$ ) was incubated during $30 \mathrm{~min}$ with $100 \mu \mathrm{L}$ of the CH138 antibody diluted 1:66 in RPMI 1640 with $1 \%$ BSA. After incubation, cells were centrifuged and washed. Cells were labeled with $100 \mu \mathrm{L}$ of a FITClabeled secondary antibody (STAR9B, Serotec, Oxford, UK.) diluted 1:250 in RPMI 1640 with 1\% BSA during $30 \mathrm{~min}$ in the dark on ice. After incubation, cells were centrifuged and washed. The PMN pellet was fixed by adding $500 \mu \mathrm{L}$ of a $1 \%$ paraformaldehyde solution in PBS and stored in the dark at $4^{\circ} \mathrm{C}$ until measurement by flow cytometry.

Once the gate for the PMN population was defined, apoptosis and necrosis was determined by plotting log FL2 (PI) vs. log FL1 (Annexin-V-FITC). Percentage of PMN that were positive for Annexin-V-FITC and negative for PI because of their membrane integrity were considered apoptotic. Percentage of PMN that were pos- itive for PI and Annexin-V-FITC were considered necrotic. Data were corrected for autofluorescence, which was defined as the fluorescence associated with nonlabeled freshly isolated PMN.

\section{Statistical Analyses}

The effect of endogenous $17 \beta$-estradiol and progesterone levels on diapedesis capacity (i.e., number of migrated PMN) and viability (\%) (i.e., $100-\%$ necrotic PMN - \% apoptotic PMN) before and after diapedesis was studied by simple linear regression. The 3 treatments (17 $\beta$-estradiol, progesterone, and dexamethasone) and the control samples were compared for PMN viability before diapedesis by the mixed model with cow as random effect and treatment as fixed effect. Pairwise comparisons between the treatments were adjusted by Tukey's multiple comparisons procedure. The effect of the treatment and type of cell layer on viability, diapedesis capacity, the number of viable PMN (i.e., number of migrated $\mathrm{PMN} \times \%$ viability) and the ratio of viable PMN after and before migration was assessed by the mixed model with cow as random effect and the treatment, type of cell layer, and their interaction as fixed effects. The effect of treatment and cell layer type on apoptosis and necrosis of PMN was assessed as described for viability.

\section{RESULTS}

\section{Influence of Endogenous $17 \beta$-Estradiol and Progesterone Concentrations}

Plasma concentrations ranged from 21 to $274 \mathrm{pg} / \mathrm{mL}$ for $17 \beta$-estradiol with a mean value of $94 \pm 24$ (SEM) $\mathrm{pg} / \mathrm{mL}$ and from 0.4 to $3.55 \mathrm{ng} / \mathrm{mL}$ for progesterone with a mean value of $1.65 \mathrm{ng} / \mathrm{mL} \pm 0.25$ (SEM).

No significant influence of endogenous $17 \beta$-estradiol $(P=0.38)$ or progesterone levels $(P=0.56)$ on the diapedesis capacity of bovine blood PMN was found $(n=13)$. Furthermore, endogenous $17 \beta$-estradiol or progesterone levels did not significantly influence viability before ( $P=0.90$ and $P=0.63$, respectively) or after diapedesis $(P=0.43$ and $P=0.79$, respectively) $(\mathrm{n}=7)$.

\section{Influence of Treatment and Cell Layer Type}

Influence on viability before migration. Before migration, the mean value for viability (91\%) was slightly higher for dexamethasone $(\mathrm{n}=7)$ than for control (88\%), $17 \beta$-estradiol (86\%), and progesterone (83\%) ( $\mathrm{n}=11, \mathrm{n}=9$, and $\mathrm{n}=7$, respectively). A significant pairwise difference in viability was only found between dexamethasone and progesterone treatment $(P=$ 0.0043). 


\section{Influence on Diapedesis Capacity and Viability After Migration}

Following migration, the treatment $(P=0.0014)$ and cell layer type $(P<0.0001)$ had an effect on the number of viable PMN in the lower compartment of the model; a significant interaction between treatment and cell layer type was found $(P=0.0136)$. The number of viable PMN in the lower compartment is determined by the number of migrated PMN and the percentage viability of these cells after migration. Both the treatment $(P=$ $0.003)$ and cell layer type $(P<0.0001)$ had a significant effect on the number of migrated PMN, with a significant interaction $(P=0.013)$ occurring between treatment and cell layer type. The percentage viability after migration was influenced by treatment $(P=0.006)$ and cell layer type $(P=0.0001)$ with again a significant interaction $(P=0.028)$.

Influence of 17ß-estradiol treatment. A significantly lower number of viable PMN in the lower compartment was found after $17 \beta$-estradiol treatment as compared with the control $(P=0.008)$ and the dexamethasone treatment $(P=0.0004)$. The influence of $17 \beta$ estradiol treatment was only significant after migration through collagen $(P=0.0294$ and $P=0.0146$ for $17 \beta$ estradiol compared with control and dexamethasone, respectively) and not for migration through epithelial cells with or without fibroblasts (Figure 1A). Regarding the influence of $17 \beta$-estradiol on the number of migrated PMN and percentage viability after migration, significant differences were found between $17 \beta$-estradiol compared with the control (diapedesis: $P=0.058$; viability: $P=0.0099$ ) and the dexamethasone treatment (diapedesis: $P=0.004$; viability: $P=0.0033$ ) (Figure 1B, 1C).

Influence of progesterone treatment. No significant influence on the number of viable PMN was found after progesterone treatment of any of the cell layers (Figure 1A).

Influence of dexamethasone treatment. No significant effects on the number of viable PMN were found between dexamethasone treatment and control regardless of cell layer type. However, when comparing the dexamethasone treatment with $17 \beta$-estradiol, a significant increase in number of viable PMN was found after migration through collagen $(P=0.0052)$ (Figure $1 \mathrm{~A})$.

Influence of cell layer type. After migration through collagen, a significantly higher number of viable PMN was found compared with migration through epithelial cells $(P<0.0001)$, but no extra significant effect was found by adding fibroblasts to the epithelial cell layer $(P=0.73)$. After $17 \beta$-estradiol or progesterone treatment, the decrease in the number of viable PMN after migration through epithelial cells was no longer significant (Figure 1A).

For diapedesis capacity and viability after migration, the same pairwise significant differences were found between collagen and the 2 other cell layer types (diapedesis: $P<0.01$, viability: $P<0.01)$. Moreover, viability was significantly influenced by adding fibroblasts $(P=$ 0.0503) (Figure 1B, 1C).

Influence on apoptosis and necrosis. When discriminating the nonviable $\mathrm{PMN}$ population in apoptotic vs. necrotic cell populations, only apoptosis $(P<0.0001)$ of bovine blood PMN was influenced by the cell layer and not necrosis $(P=0.165)(\mathrm{n}=7)$. Adding fibroblasts to epithelial cells caused an extra, significant effect on apoptosis $(P=0.038)$ (Figure 2). No significant effect of the treatment on apoptosis or necrosis was found (Table 1).

Influence on ratio of viable PMN after and before migration. The influence of treatment and cell layer type on the ratio of viable PMN after and before migration (i.e., number of migrated $\mathrm{PMN} \times$ viability after diapedesis/initial number of $\mathrm{PMN} \times$ viability before diapedesis) was statistically assessed to adjust for possible differences in viability just before migration. The same significant differences were found as for number of migrated PMN. A significantly lower ratio was found after $17 \beta$-estradiol treatment compared with the control $(P=0.008)$ and dexamethasone treatments $(P=$ $0.0004)$. The influence of $17 \beta$-estradiol treatment was only significant after migration through collagen $(P=$ 0.0294 and $P=0.0146$ for $17 \beta$-estradiol compared with the control and dexamethasone, respectively) and not for migration through epithelial cells with or without fibroblasts.

\section{DISCUSSION}

The PMN used in our study were isolated from cows in the last month of gestation. In this period, $17 \beta$-estradiol levels rise progressively until the last week before parturition. In the last week of gestation, $17 \beta$-estradiol levels start to increase more extensively, peaking in the last $3 \mathrm{~d}$ before delivery (Bell, 1995). During the last month of gestation, the high concentration of progesterone tends to decline, but a dramatic fall usually occurs only in the last $2 \mathrm{~d}$ before delivery. Ovariectomy is sometimes used to obtain constant and minimal sex steroid hormone levels and to eliminate the complexity of the periparturient physiology. This approach was not indicated in this study because the presence of a sufficient level of $17 \beta$-estradiol and progesterone can be essential for target cell expression of steroid hormone receptors (Atwood et al., 2000; Lamote et al., 2004). However, it should be noted that there is no unequivocal 


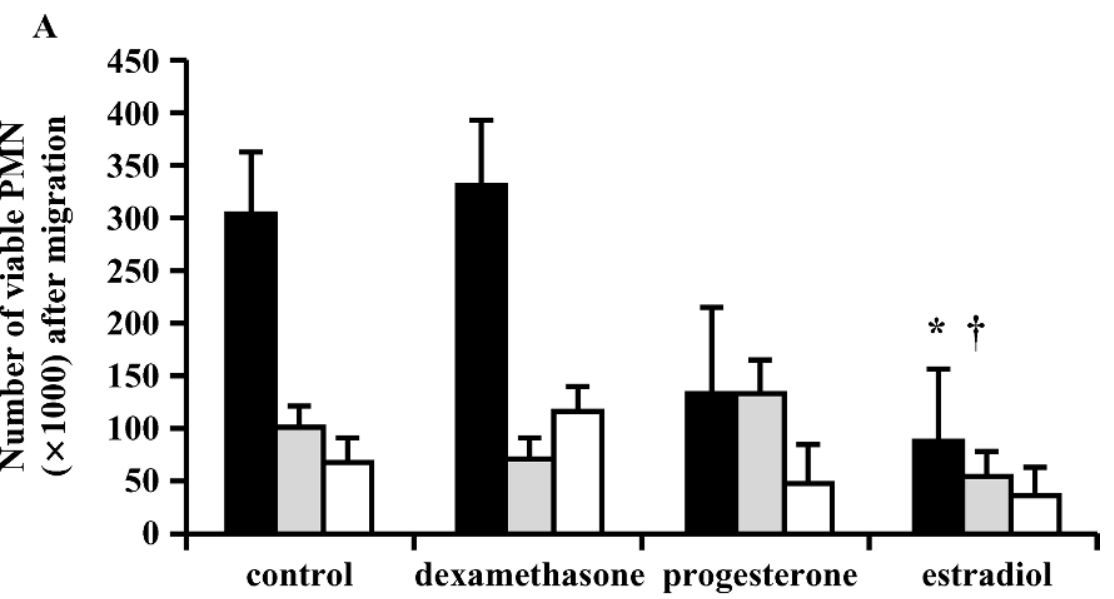

Treatment
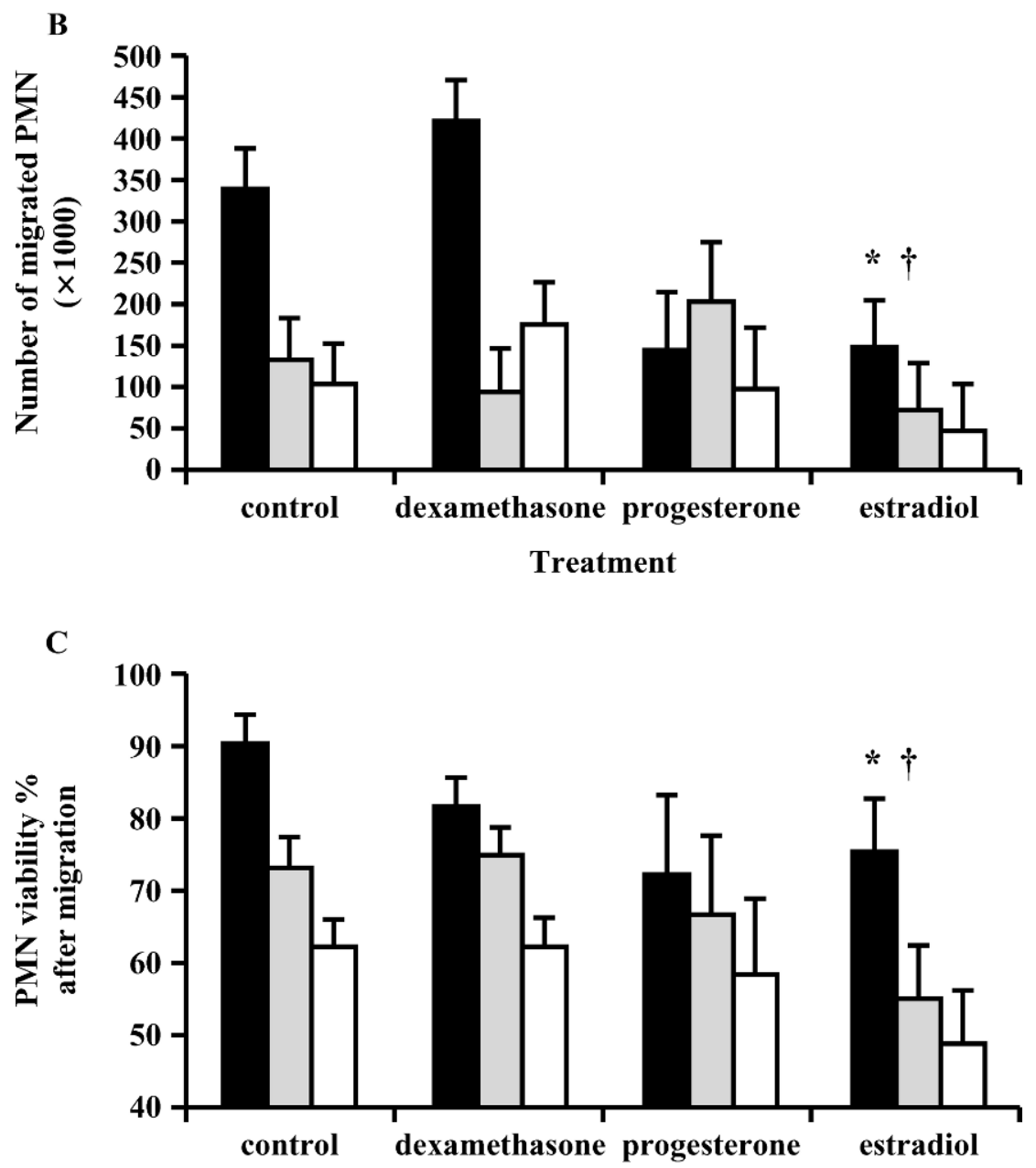

\section{Treatment}

Figure 1. A. Influence of treatment on the number of viable PMN migrated through different cell layers (numbers are means \pm SEM). B. Influence of treatment on the diapedesis capacity (i.e., number of migrated PMN) of PMN (numbers are means \pm SEM). C. Influence of treatment on the viability (100 - \% necrotic PMN - \% apoptotic PMN) of PMN migrated through different cell layers (numbers are means \pm SEM); $* P<0.05$ vs. control, $\dagger P<0.05$ vs. dexamethasone. Black bars = collagen, gray bars $=$ epithelial cells, and open bars $=$ epithelial cells with fibroblasts. 


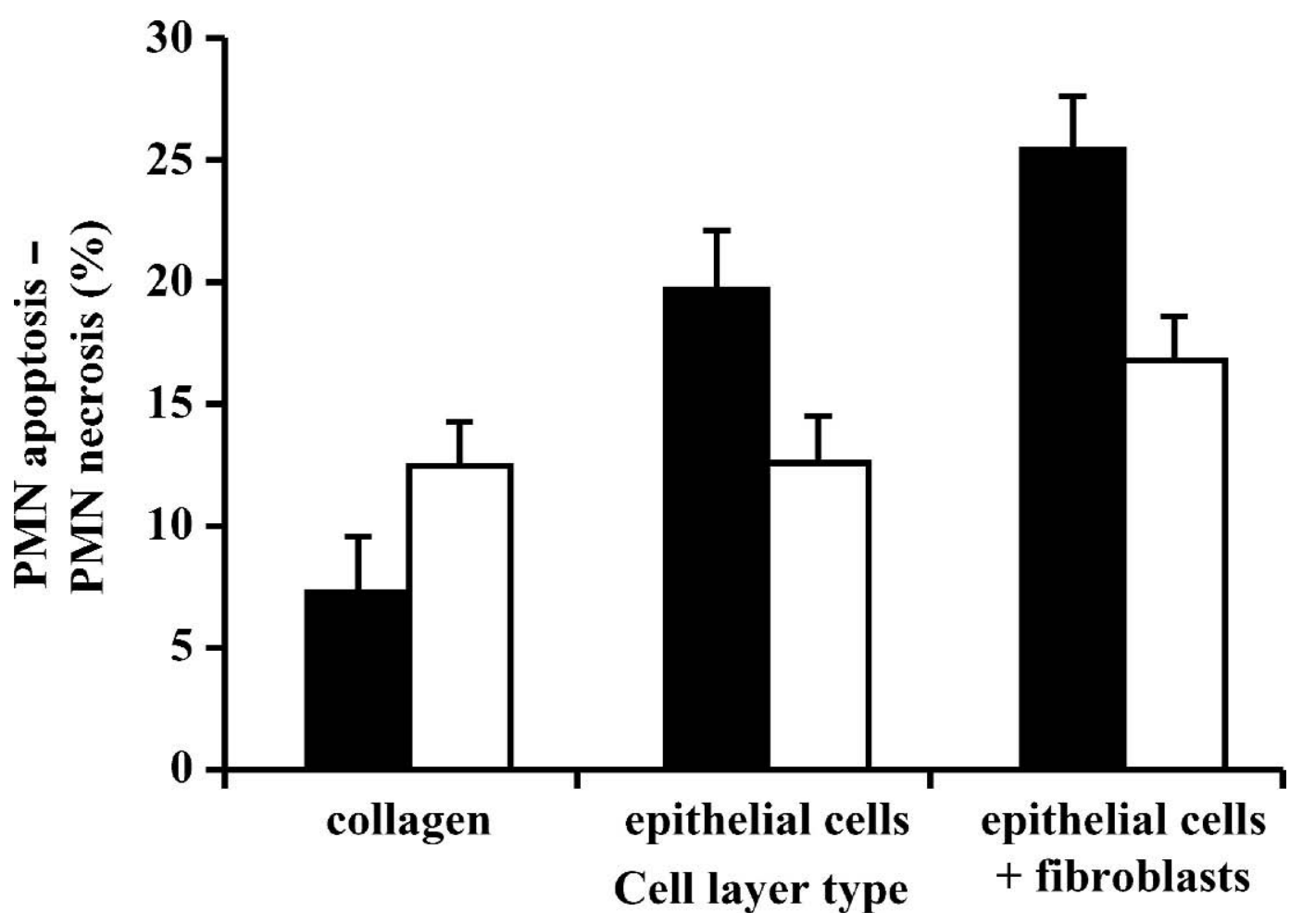

Figure 2. Influence of migration through different cell layers on the apoptosis (\%) and necrosis (\%) of PMN (numbers are means \pm SEM). Black bars = apoptosis, open bars = necrosis.

evidence on the presence of estrogen and progesterone receptors in bovine PMN (Boos et al., 1996; Winters et al., 2003).

A remarkable aspect from the current study, as well as from previous studies in cows (Smits et al., 1996) and sows (Osterlundh et al., 2002), was the high variability in PMN chemotactic ability observed between the individual animals. It was therefore tested whether this interanimal variability, which can be responsible for intercow differences in resistance against mastitis (for review see Burvenich et al., 2003), is correlated with the endogenous $17 \beta$-estradiol and progesterone levels before PMN isolation. Because no correlation was found between the endogenous $17 \beta$-estradiol and progesterone levels and diapedesis capacity, it can be concluded that slight changes in these hormone levels during late gestation are not responsible for the observed intercow differences. Neither was the high intercow variability observed in our study caused by differences in viability just before migration, because the same results were found for number of viable PMN and ratio of viable PMN after and before migration. Our finding concerning the influence of endogenous $17 \beta$-estradiol and progesterone levels on diapedesis is supported by the study from Subandrio et al. (2000), although contradictory results are reported in the literature. Compari-

Table 1. Influence of $17 \beta$-estradiol, progesterone, and dexamethasone on apoptosis and necrosis after migration through collagen-coated inserts and collagen-coated inserts with bovine mammary epithelial cells (BME) (mean values).

\begin{tabular}{lrccc}
\hline & Control & $17 \beta$-Estradiol & Progesterone & Dexamethasone \\
\hline Apoptosis (\%) after migration & & & & \\
Collagen & 3.40 & 4.83 & 11.83 & 9.08 \\
BME & 15.21 & 23.09 & 25.04 & 15.56 \\
BME + fibroblasts & 23.94 & 30.22 & 21.74 & 25.63 \\
Necrosis (\%) after migration & & & & \\
Collagen & 5.82 & 19.64 & 15.53 & 8.92 \\
BME & 11.30 & 21.75 & 8.02 & 9.44 \\
BME + fibroblasts & 13.80 & 21.12 & 19.87 & 11.97 \\
\hline
\end{tabular}


son between different studies is complicated by the use of different migration techniques, e.g., random vs. directed migration. Subandrio et al. (2000) evaluated the chemotactic ability of blood PMN isolated from cows in estrus, diestrus, and after ovariectomy and could not observe a significant difference between the different reproductive stages. However, Roth et al. (1983) found an enhanced random migration with increased serum $17 \beta$-estradiol and progesterone concentrations suggesting an influence of sex steroid hormones on PMN function during the normal estrous cycle.

Before migration, no significant influence of $17 \beta$-estradiol, progesterone, or dexamethasone treatment on PMN viability was found compared with the control. The scarce reports concerning the influence of $17 \beta$-estradiol and progesterone on viability of blood PMN are restricted to apoptosis of human PMN and reveal conflicting results. Cox (1995) and Liles et al. (1995) have reported that progesterone has no influence on the apoptosis of blood PMN, whereas Molloy et al. (2003) describe that physiological doses of $17 \beta$-estradiol and progesterone cause a delay in spontaneous apoptosis, associated with a noticeable increase in PMN survival and a more adequate immune response during pregnancy in humans. More information is available on dexamethasone treatment of PMN, although it is also restricted to humans. Inhibition of PMN apoptosis was found for dexamethasone treatment by Cox (1995), Cox and Austin (1997), Liles et al. (1995), and Meagher et al. (1996). The high viability of PMN in the control samples after $3 \mathrm{~h}$ of incubation in our study made it more difficult to measure a significant inhibition of apoptosis by dexamethasone. However, when compared with progesterone treatment, where viability was lowest after $3 \mathrm{~h}$ of incubation, the positive effect of dexamethasone on PMN viability was indeed significant. A positive influence of dexamethasone on the PMN viability is therefore not excluded. It can be suggested that the viability of control samples would have decreased after a longer incubation period, so that the difference with the dexamethasone treatment would have been more clearly expressed. Nevertheless, a 3 -h incubation period was chosen to guarantee a high viability just before migration.

The influence of steroid hormone treatment and cell layer type on diapedesis and viability after migration was evaluated by the number of viable PMN in the lower compartment of the in vitro model (number of migrated $\mathrm{PMN} \times \%$ viability after migration). $17 \beta$-estradiol significantly reduced the number of viable PMN after migration through collagen, although this suppressive effect was no longer significant when other cell layers were added. Because a less efficient migration through epithelial cells is evident from our data and the literature (Smits et al., 2000), the significance of $17 \beta$-estradiol treatment may be masked by adding epithelial cells to the model. Alternatively, it has been suggested that migration through collagen is mediated by mechanisms other than migration through epithelial cells (Parkos, 1997). The negative influence of $17 \beta$-estradiol on the number of viable PMN is caused by an influence on the diapedesis capacity as well as by an effect on the viability after migration. As described above, this was not due to a lower viability before migration nor was it caused by differences in endogenous $17 \beta$-estradiol or progesterone levels. A potential role in the mechanism of immune depression around parturition can be suggested for $17 \beta$-estradiol, whose levels typically peak at parturition. Previous studies support the hypothesis that sex steroids reduce PMN chemotaxis of bovine (Subandrio et al., 2000), equine (Watson et al., 1987), or human (Miyagi et al., 1992) PMN following in vivo administration of $17 \beta$-estradiol or after in vitro treatment with $17 \beta$-estradiol. However, these reports are restricted to the influence on chemotaxis; the influence on migration through epithelial cells and fibroblasts has not been considered previously in vitro. By adding epithelial cells and fibroblasts, interaction of these cells with PMN is also considered, although the role of endothelial cells is not taken into account. It should be noted that comparison of our results with the literature data is not completely straightforward because of species differences, the differences in endogenous or exogenous steroid hormone concentrations, or both, and the different types of migration (diapedesis vs. chemotaxis and random migration) studied. Nevertheless, a general conclusion from our study and from the literature is the suppressive effect of $17 \beta$-estradiol on PMN migration. This effect can be mediated by interaction of $17 \beta$-estradiol with its receptor. However, the presence of estrogen receptors on bovine PMN has not yet been demonstrated. An alternative hypothesis is that the effect of $17 \beta$-estradiol is not receptor mediated. Because other cells $(<10 \%)$ are present in the PMN isolates, we cannot exclude the possibility that $17 \beta$ estradiol exerts its influence on PMN in a paracrine way.

In the current study, progesterone had no significant influence on the number of viable PMN compared with the control. Conflicting findings are reported for progesterone in literature. In the study of Subandrio et al. (2000), a significant reduction in PMN chemotaxis is reported following progesterone treatment of ovariectomized cows. Random migration of blood PMN is reduced by progesterone administration to ovariectomized mares as well as by in vitro progesterone treatment of PMN from acyclic ponies (Watson et al., 1987). However, Miyagi et al. (1992) reported that progesterone 
slightly enhances the chemotactic ability of human PMN.

Although no significant influence was observed for dexamethasone treatment compared with the control, a significant stimulating effect was noted, compared with $17 \beta$-estradiol. This finding may support a role for dexamethasone in the recovery from a depressed number of viable PMN at the site of infection by $17 \beta$-estradiol. Again, contradictory results are reported in the literature. Dexamethasone administration to cattle results in an increase of PMN chemotaxis (Anderson et al., 1999), whereas in vitro dexamethasone treatment of human PMN causes a significant fall in chemotaxis (Lomas et al., 1991).

The subsequent removal of PMN from the site of infection by apoptosis after performance of their function is as important as efficient migration to the site of infection, because the release of histotoxic granules into the surrounding tissue should be prevented. Once PMN migrate out of the circulatory system, they die spontaneously by apoptosis, are recognized by macrophages, and are cleared from the site of infection (Sladek and Rysanek, 2000). In the current study, a significant decrease in PMN viability, attributable to a significant increase in PMN apoptosis but not necrosis, was found after migration through a BME cell layer, with or without fibroblasts, compared with migration through models coated only with collagen. It should be noted that use of primary BME cells in our in vitro model gave similar results (Lamote et al., 2003). Our results suggest that diapedesis through BME cells, stimulated by ZAS, induces PMN apoptosis. The mechanism by which epithelial cells induce PMN apoptosis remains to be elucidated, although a role for the $\beta_{2}$-integrin subunits CD11b and CD18 has been suggested in humans. $\beta_{2^{-}}$ Integrins may play an important role in the stimulation of apoptosis, because CD18-deficient mice show depressed PMN apoptosis (Weinmann et al., 2003). Furthermore, the importance of CD11b and CD18 in enhancing tumor necrosis factor- $\alpha$-stimulated apoptosis was shown by Walzog et al. (1997). This hypothesis was negated by Larsson et al. (2000), who reported that antiCD18 antibodies could stimulate apoptosis thus suggesting an inhibitory role for CD18.

In conclusion, in our study it has been shown that $17 \beta$-estradiol suppresses the chemotactic ability as well as the viability of bovine blood PMN after migration through an in vitro model. The importance of epithelial cells but not fibroblasts as an inductor of apoptosis was also demonstrated. Although these important phenomena require further research with respect to their underlying mechanism of action, our results can contribute to a better understanding of the mechanism of immune depression around parturition.

\section{ACKNOWLEDGMENTS}

This study was partly supported by the Bijzonder Onderzoeksfonds of Ghent University (BOF, grant number 01111401 to I. Lamote) and by the National Fund for Scientific Research (FWO, grant number 3G008699). The authors wish to thank P. Rainard for the determination of the C5a concentration and M. Corijn, K. Demeyere, and E. Vander Elstraeten for the excellent technical assistance.

\section{REFERENCES}

Anderson, B., D. Watson, and I. Colditz. 1999. The effect of dexamethasone on some immunological parameters in cattle. Vet. Res. Commun. 23:399-413.

Atwood, G., R. Hovey, J. Glover, G. Chepko, E. Ginsburg, W. Robinson, and B. Vonderhaar. 2000. Progesterone induces side-branching of the ductal epithelium in the mammary glands of peripubertal mice. J. Endocrinol. 167:39-52.

Bell, A. 1995. Regulation of organic nutrient metabolism during transition from late pregnancy to early lactation. J. Anim. Sci. 73:2804-2819.

Boos, A., W. Meyer, R. Schwarz, and E. Grunert. 1996. Immunohistochemical assessment of oestrogen receptor and progesterone receptor distribution in biopsy samples of the bovine endometrium collected throughout the oestrous cycle. Anim. Reprod. Sci. 44:11-21.

Burton, J., and R. Erskine. 2003. Immunity and mastitis. Some new ideas for an old disease. Vet. Clin. Food Anim. 19:1-45.

Burvenich, C., M. Paape, D. Hoeben, H. Dosogne, A. Massart-Leën, and J. Blum. 1999. Modulation of the inflammatory reaction and neutrophil defense of the bovine lactating mammary gland by growth hormone. Domest. Anim. Endocrinol. 17:149-159.

Burvenich, C., V. Van Merris, J. Mehrzad, A. Diez-Fraile, and L. Duchateau. 2003. Severity of $E$. coli mastitis is mainly determined by cow factors. Vet. Res. 34:521-564.

Cox, G. 1995. Glucocorticoid treatment inhibits apoptosis in human neutrophils. Separation of survival and activation outcomes. J. Immunol. 154:4719-4725.

Cox, G., and R. Austin. 1997. Dexamethasone-induced suppression of apoptosis in human neutrophils requires continuous stimulation of new protein synthesis. J. Leukoc. Biol. 61:224-230.

Henry, M., A. Figueiredo, M. Palhares, and M. Coryn. 1987. Clinical and endocrine aspects of the oestrus cycle in donkeys (Equus asinus). J. Reprod. Fertil. 35(Suppl.):297-303.

Kato, T., Y. Takeda, T. Nakada, and F. Sendo. 1995. Inhibition by dexamethasone of human neutrophil apoptosis in vitro. Nat. Immun. 14:198-208.

Lamote, I., K. Demeyere, E. Meyer, and C. Burvenich. 2003. Influence of sex steroid hormones and diapedesis on the viability of bovine polymorphonuclear leukocytes. Eur. J. Physiol. 446:R1-R8.

Lamote, I., E. Meyer, A. Massart-Leën, and C. Burvenich. 2004. Sex steroids and growth factors in the regulation of mammary gland proliferation, differentiation, and involution. Steroids 69:145159.

Larsson, J., L. Serrander, O. Stendahl, and H. Lundqvist-Gustafsson. 2000. Involvement of the beta(2)-integrin CD18 in apoptosis signal transduction in human neutrophils. Inflamm. Res. 49:452459.

Liles, C., D. Dale, and S. Klebanoff. 1995. Glucocorticoids inhibit apoptosis of human neutrophils. Blood 86:3181-3188.

Lomas, D., A. Chamba, and R. Stockley. 1991. The effect of in vitro and in vivo dexamethasone on human neutrophil function. Agents Actions 33:279-285.

Meagher, L., J. Cousin, J. Seckl, and C. Haslett. 1996. Opposing effects of glucocorticoids on the rate of apoptosis in neutrophilic and eosinophilic granulocytes. J. Immunol. 156:4422-4428. 
Mehrzad, J., H. Dosogne, E. Meyer, R. Heyneman, and C. Burvenich. 2001. Respiratory burst activity of blood and milk neutrophils in dairy cows during different stages of lactation. J. Dairy Sci. 68:399-415.

Miyagi, M., H. Aoyama, M. Morishita, and Y. Iwamoto. 1992. Effects of sex hormones on chemotaxis of human peripheral polymorphonuclear leukocytes and monocytes. J. Periodontol. 63:28-32.

Molloy, E., A. O'Neill, J. Grantham, M. Sheridan-Pereira, J. Fitzpatrick, D. Webb, and R. Watson. 2003. Sex-specific alterations in neutrophil apoptosis: The role of estradiol and progesterone. Phagocytes 102:2653-2659.

Nittoh, T., H. Fujimore, Y. Kozumi, K. Ishihara, S. Mue, and K. Ohuchi. 1998. Effects of glucocorticoids on apoptosis of infiltrated eosinophils and neutrophils in rat. Eur. J. Pharmacol. 354:73-81.

Osterlundh, I., F. Hulten, A. Johannisson, and U. Magnusson. 2002. Sows intramammarily inoculated with Escherichia coli at parturition: I. functional capacity of granulocytes in sows affected or non-affected by clinical mastitis. Vet. Immunol. Immunopathol. 90:35-44.

Parkos, C. 1997. Cell adhesion and migration I. Neutrophil adhesive interactions with intestinal epithelium. Am. J. Physiol. G763G768.

Rainard, P. 2003. The complement in milk and defense of the bovine mammary gland against infections. Vet. Res. 34:647-650.

Rainard, P., P. Sarradin, and B. Poutrel. 1998. Quantification of $\mathrm{C} 5 \mathrm{a} / \mathrm{C} 5 \mathrm{a}$ (desArg) in bovine plasma, serum and milk. Vet. Res. 29:73-88.

Roets, E., C. Burvenich, A. Diez-Fraile, and E. Noordhuizen-Stassen. 1999. Evaluation of the role of endotoxin and cortisol on modulation of CD18 adhesion receptors in cows with mastitis caused by Escherichia coli. Am. J. Vet. Res. 60:2-9.

Roth, J., M. Kaeberle, L. Appell, and R. Nachreiner. 1983. Association of increased estradiol and progesterone blood values with altered bovine polymorphonuclear leukocyte function. Am. J. Vet. Res. 44:247-253.
Sladek, Z., and D. Rysanek. 2000. Apoptosis of polymorphonuclear leukocytes of the juvenile bovine mammary gland during induced influx. Vet. Res. 31:553-563.

Smits, E., C. Burvenich, A. Guidry, and A. Massart-Len. 2000. Adhesion receptor CD11b/CD18 contributes to neutrophil diapedesis across the bovine blood-milk barrier. Vet. Immunol. Immunopathol. 73:255-265.

Smits, E., E. Cifrian, A. Guidry, P. Rainard, C. Burvenich, and M. Paape. 1996. Cell culture system for studying bovine neutrophil diapedesis. J. Dairy Sci. 79:1353-1360.

Subandrio, A., I. Sheldon, and D. Noakes. 2000. Peripheral and intrauterine neutrophil function in the cow: The influence of endogenous and exogenous sex steroid hormones. Theriogenology 53:1591-1608.

Van Oostveldt, K., H. Dosogne, C. Burvenich, M. Paape, V. Brochez, and E. Van den Eeckhout. 1999. Flow cytometric procedure to detect apoptosis of bovine polymorphonuclear leukocytes in whole blood. Vet. Immunol. Immunopathol. 70:125-133.

Walzog, B., F. Jeblonski, A. Zakrzewicz, and P. Gaehtgens. 1997. Beta (2) integrins (CD11/CD18) promote apoptosis of human neutrophils. FASEB J. 11:1177-1186.

Watson, E., C. Stokes, and F. Bourne. 1987. Influence of administration of ovarian steroids on the function of neutrophils isolated from the blood and uterus of ovariectomized mares. J. Endocrinol. 112:443-448.

Weinmann, P., K. Scharffetter-Kochanek, S. Forlow, T. Peters, and B. Walzog. 2003. A role for apoptosis in the control of neutrophil homeostasis in the circulation: Insights from CD18-deficient mice. Blood 101:739-746.

Winters, K., E. Meyer, V. Van Merris, W. Van Den Broeck, L. Duchateau, and C. Burvenich. 2003. Sex steroid hormones do not influence the oxidative burst activity of polymorphonuclear leukocytes from ovariectomized cows in vitro. Steroids 68:397-406.

Zavizion, B., M. Van Duffelen, W. Schaeffer, and I. Politis. 1996. Establishment and characterization of a bovine mammary epithelial cell line with unique properties. In Vitro Cell. Dev. Biol. $32: 138-148$ 